\title{
Sensibilidades e imágenes generizadas del 'yo' en la década del ' 40. Lo visual y el dispositivo fotográfico en la construcción de la masculinidad*
}

\section{Andrea Torricella**}

\section{Resumo}

En este trabajo analizo un corpus de fotografías personales de un hombre en la década de 1940 en Argentina, rastreando los modos en que lo visual y la fotografía operan como instancias de construcción de subjetividades generizadas. También recorro algunos estereotipos masculinos de la época y sus posibles vínculos con las visualizaciones masculinas en las fotografías.

Palavras-chave: Masculinidad, Fotografía, Cuerpo, Género, Imágenes del Yo.

* Recebido para publicação em agosto de 2008, aceito em fevereiro de 2009.

** Universidad Nacional de Mar del Plata - Becaria Doctoral de Conicet Argentina. andreatorricella@ciudad.com.ar 
Sensibilidades e imágenes generizadas del 'yo' en la década del '40

Sensibilities and Gendered Images of the Self in the 40's. The Visual and the Photographic Device in the Construction of Masculinity

\begin{abstract}
In this paper I examine a set of personal photographs belonging to a man in 1940. My aim is to demonstrate the ways in which the visual and the photographic device produce gendered subjectivities. I also present some masculine stereotypes from that period and analyze the ways in which they are represented in the photographs of masculine visualities.
\end{abstract}

Key Words: Masculinity, Photography, Body, Gender, Images of the Self. 


\section{1) Introducción}

El que sigue es un trabajo de investigación con imágenes y sobre imágenes fotográficas que problematiza las relaciones entre lo visual y lo identitario. ${ }^{1}$ En su (relativamente) reciente Visto y no visto, Peter Burke (2001) remarcaba el sentido ilustrativo que las imágenes habían tenido dentro de la historiografía, invitando - a partir de un trabajo de síntesis y valoración de perspectivas - a explorar este yacimiento de testimonios para el trabajo histórico. ${ }^{2}$

Si la mirada rebasa el campo disciplinar de la Historia, se pueden encontrar diseminados varios trabajos que apuestan en el mismo sentido que Burke argüía. Quisiera subrayar el papel protagónico que los estudios de mujeres y de género han tenido en esta proliferación de investigaciones. La crítica feminista (política y académica o académico-política) de las formas de representación de las mujeres trazó una línea iniciadora en estudios visuales (De Lauretis, 1992; Mulvey, 1989; Kuhn, 1994; Bonner y otros, 1992; Shiach, 1999; Laguarda, 2006).

En la última década, el interés no está puesto solamente en la denuncia o descripción de estereotipos visuales, sino también -y principalmente- en el análisis de las formas en que esas imágenes son operativas, constitutivas de modos de ser y sensibilidades.

\footnotetext{
${ }^{1}$ Quiero agradecer las valiosas sugerencias que realizaron a una primera versión de este texto Nicolás Quiroga, mis compañeros del Grupo de Estudios sobre Familia, Género y Subjetividades de la Universidad Nacional de Mar del Plata (Argentina), así como la lectura y comentarios de Dora Barrancos, Beatriz Ruibal y Norberto Álvarez.

2 De 2001 es también la primera edición en inglés por la editorial londinense Reaktion Books. Algunas razones de este tardío encuentro entre lo visual y la historia se podrían ubicar en la poca legitimidad que tienen las fuentes iconográficas en comparación con las escritas (lo mismo ocurrió con las fuentes orales en su momento); pero también en la escasez de habilidades que la formación disciplinar otorga para con este tipo de materiales (Kossoy, 2001). Los trabajos de reflexión sobre fotografía o historia de la fotografía tienen una trayectoria más larga. Tres trabajos pioneros y de referencia obligada son los de Giselle Freund (1993), Susan Sontag (1996) y Roland Barthes (2003).
} 
Según la especialista Griselda Pollock (2000), esta transformación estaría basada en el abandono de una definición de imagen como deformación o falsificación (copia) de otra cosa llamada realidad ${ }^{3}$ :

Aquí, mujer/mujeres deja de ser el objeto de la representación. En cambio, se torna posible que la función de la representación sea producir la diferencia sexual para la cual una determinada imagen del cuerpo es el significante. La representación es uno de los muchos procesos sociales por los cuales órdenes específicos de diferencia sexual (internamente diferenciados a través de los ejes de clase, raza, sexualidad, edad, habilidades, etc.) son incesantemente construidos, modificados, resistidos y reconstituidos. El tema es si se puede trascender la idea de que las representaciones son síntomas de causas externas a ellas (sexismo, patriarcado, capitalismo, racismo, imperialismo) y aprender a comprender su rol activo en la producción de esas categorías. Las representaciones articulan/producen significados así como re-presentan un mundo que ya significa (Pollock, 2000: 233). ${ }^{4}$

${ }^{3}$ Esta autora traza a través de una comparación entre un artículo de ella de 1977 un cambio de paradigma: el reemplazo del estudio de las "imágenes de mujeres" al de "representación/sexualidad/feminidad". En este primero, a la par que las feministas rechazaban las definiciones sociales de los roles y esferas consideradas femeninas, contestaban también las imágenes de mujeres socialmente aceptables.

4 "Here, woman/women cease to be the topic of representation. Instead, it becomes possible to perceive that the function of representation is the production of sexual differentiation for which a certain body image is the signifier. Representation is one of the many social processes by which specific orders of sexual difference (internally differentiated across the axes of class, race, sexuality, age, ability and so forth) are ceaselessly constructed, modified, resisted, and reconstituted. The issue here is to whether we can transcend the idea that representations are symptoms of causes external to them (sexism, patriarchy, capitalism, racism, imperialism) and learn to understand their active role in the production of those categories. Representations articulate/produce meanings as well as re-presenting a world already meaningful" [Traducción al español de la autora]. 
En el caso particular de los estudios visuales de representaciones masculinas, estos diversos usos de las imágenes han coexistido dado el reciente interés sobre estos temas y la nutrición que este espacio ha tenido de las contribuciones feministas. Sin embargo, en gran parte de los trabajos sobre representaciones visuales de género, los hombres, la masculinidad y el cuerpo masculino se caracterizan por su poder para controlar y manipular (otras) cosas (Pultz, 1995).

Este trabajo que aquí presento, es una continuación y focalización en torno a mis investigaciones sobre cómo se construye la diferencia sexual y lo familiar a través del registro visual (Torricella y Pérez, 2005; Torricella, 2007). Mi objetivo en este artículo es analizar las formas en que se edifica una experiencia y una sensibilidad diferenciada de género y cómo lo visual (en este caso a través de fotografías personales) opera en esta construcción. ${ }^{5}$

Joan Scott (1999) cuestionó los usos que situaban a la "experiencia" como un punto de explicación originario. Su crítica apuntaba a problematizar el carácter construido de esta experiencia y proponía situarla como objeto de indagación antes que sitio de atestiguamiento. ${ }^{6}$ Quisiera retomar este planteamiento para hacer una analogía con los modos de interpretación de lo visual (y la metáfora visual en las formas de explicación) y presentar la opción metodológica que se sigue en mis trabajos.

Si bien se podría afirmar que el acto de producción mecánica de la imagen fotográfica le otorga un relativo carácter testimonial y evidencial (la irrefutable presencia del referente en la fotografía que hablaba Barthes y que retoma Dubois (1982) al

\footnotetext{
5 Aunque no todos incorporan la perspectiva de género, con "sensibilidades" hago referencia a los trabajos de Norbert Elías (1993) y José Pedro Barrán (1990).

6 "La evidencia de la experiencia, entonces, se vuelve la evidencia para el hecho de la diferencia antes que un modo de explorar cómo la experiencia es establecida, cómo opera, cómo y en qué modos constituye sujetos que ven y actúan en el mundo" (Scott, 1999:63).
} 
caracterizarla como un signo indexal), mi trabajo se encamina a indagar en las formas en que se construye una visualidad diferenciada y cómo esta opera en la producción de sensibilidades generizadas. ${ }^{7}$ El cambio terminológico entre visibilización y visualización que los estudios de género han utilizado para recuperar a la mujer como sujeto de la historia es ilustrativo en este sentido. El movimiento entre visibilidad, es decir, volver visible (sinónimo también de voz) hacia visualidad, el cual acarrea connotaciones discursivas y retóricas (Hayes, 2005), es parte de mis posicionamientos metodológicos.

Este artículo está basado en una serie de fotografías en blanco y negro de un hombre, Juan (a él le pertenecían y es él quien aparece siempre retratado) todas ellas datadas de la década de 1940. Las características generales de este corpus en relación al acervo total de las fotografías de mi entrevistada ${ }^{8}$, pueden resumirse en que son todas fotografías temáticamente individualizables, que fotógrafos profesionales le tomaban a Juan en su trabajo de guardavidas en las playas de Mar del Plata y que gran parte de ellas están dispuestas en un álbum que las reúne como materialidad significativa.

Si bien analizo las fotografías y no la historia de vida de Juan, mencionaré algunos datos biográficos de mi sujeto de estudio a modo de coordenadas. Hijo de inmigrantes, nació en la ciudad balnearia de Mar del Plata (Argentina) en 1921, su madre murió cuando él era aún un niño y vivió con su padre y sus tres hermanos hasta que se casó con Rosa en 1947. Cuando la conoció dos años antes, trabajaba durante cuatro meses como guardavidas mientras que el resto del año lo hacía en una fábrica de mosaicos. Luego de casarse y de que nacieran sus tres primeros hijos

\footnotetext{
7 Aquí utilizo el concepto generización para evitar la diferenciación ontológica entre sujeto y género, como si primero existiese un sujeto al cual luego se le es asignado un género. "Generización" propone deshacerse de las metáforas de sujeto como sustancia y de género como atributo.

8 Debo remarcar que al haber fallecido Juan, accedí a las fotos y a algunos datos contextuales de las mismas a partir de las entrevistas realizadas a su esposa.
} 
(tuvieron cuatro), dejó el trabajo de guardavidas y se dedicó a llevar adelante su propia fábrica de mosaicos junto con la cooperación de su esposa.

He dividido el análisis en dos partes con objetivos particulares: en el primero, analizo las fotografías personales que Juan y su esposa conservaban. Lo fotográfico como dispositivo y como acto es resaltado en esta sección como un modo de construir sensibilidades generizadas. El ojo de los anónimos fotógrafos y la pose de Juan (¿para ellos?) serán los ejes del apartado. A fin de ampliar los modos de construcción de esa experiencialidad de género y de afinar algunas de las hipótesis, reconstruyo en la segunda parte las configuraciones visuales significativas de un tipo de masculinidad ejemplar relacionada con la contextura física, a través de la prensa, los cursos por correspondencia y el cine.

\section{2) Las fotos: imágenes del yo y masculinidad}

El retrato fotográfico supone una nueva forma de observar las caras, las expresiones, las poses y corporalidades propias y ajenas. Después de la segunda mitad del siglo XIX, la fotografía inaugura una serie de mutaciones técnicas que aún persisten y que alteran totalmente la relación con el cuerpo. En un primer momento, estos elementos técnicos están al servicio del control del movimiento humano para racionalizarlo en su eficacia como cuerpo productivo y cuerpo deportivo a través de dos registros: el mecánico-motriz y el sanitario (Michaud , 2006). La tecnología adquiere parte de su sentido como vector de una nueva representación del sujeto, una transformación en la "presentación de sí mismo" (Ory, 2006:144).

De relativamente fácil acceso a cualquiera (en comparación con el retrato pintado), la reproducción fotográfica de la imagen de sí mismo modificó las formas de mirarse (percibirse) inspeccionando modos de pararse, reírse y asemejarse con una 
noción de temporalidad particular. ${ }^{9}$ La motricidad, la espacialidad y el comportamiento son indicios de una diferenciación social de los sexos y los cuerpos (Marion Young, 1990).

Las fotografías con las que trabajo no son realizadas en contextos familiares o de camaradería. Son fotografías de profesionales "itinerantes" en la playa de Mar del Plata, quienes firmaban sus producciones y las vendían (en este caso se las regalaban a Juan). Al resaltar la pericia de quienes "apretaban el botón", sugiero la manipulación de ciertas reglas estéticas de lo que debe ser una "buena fotografía", encuadre, perspectiva, iluminación y pose. También lo que debe ser una buena representación: de lo bello, lo heroico, lo divertido, lo afectivo, lo familiar, lo ocioso; podría llamarle los topoi de la fotografía social.

En la década de 1940 el dispositivo fotográfico ya contaba con una serie de innovaciones que modificaron la relación entre técnica-pose-recorte característica de las clásicas fotografías de actitudes rígidas que se encuentran en los inicios de la práctica fotográfica.

No es mi intención postular una espontaneidad u objetividad en las imágenes construidas con estas mejoras técnicas. El carácter artificial de las tomas fotográficas es una constante aunque varía en su forma e intensidad.

¿Cómo son las fotografías que Juan y su esposa conservaban de aquella década de 1940? ¿Qué sentidos visuales pueden reconstruirse a partir de esas tomas? ¿Qué significados pueden recuperarse en relación a las masculinidades a partir del acto fotográfico entre profesionales itinerantes y unos jóvenes guardavidas? ¿Qué apropiaciones son posibles cuando es uno mismo quien re-presenta la masculinidad ejemplar?

9 Si bien podría sostener cierta analogía entre mirarse al espejo y verse en una fotografía, en la primera de estas prácticas, verse y posar son acciones simultáneas. En cambio, la fotografía precisa de un impasse entre el momento de la pose (la toma) y el de observación, permitiendo la conservación de esos instantes arrancados del tiempo. 
Fotografía n ${ }^{\circ} 1$

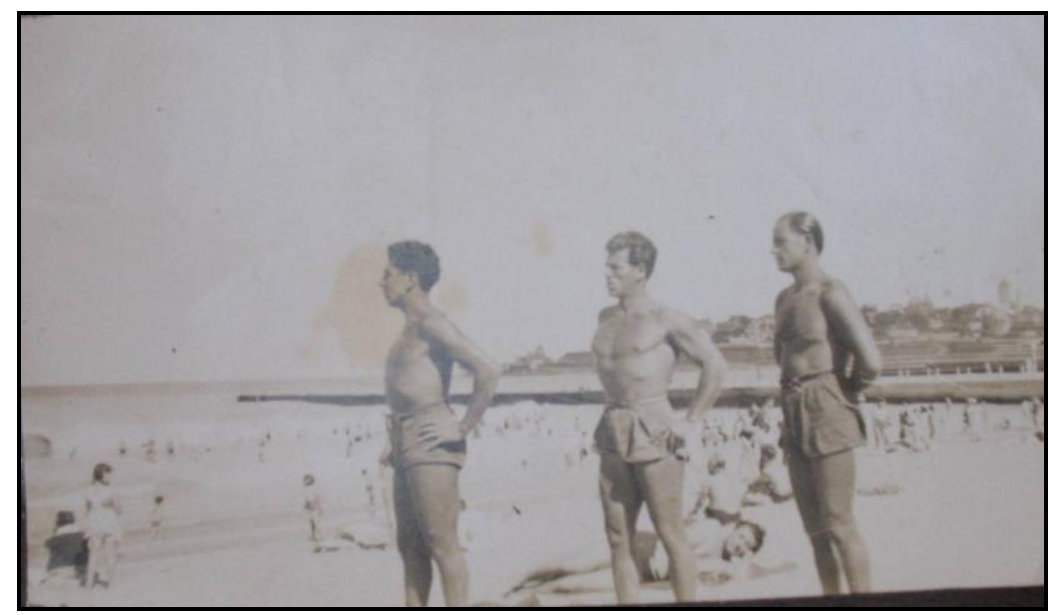

Fuente: Archivo personal de la entrevistada

La fotografía $n^{\circ} 1$ podría ser el prototipo de la imagen del espacio de la playa custodiado por los guardavidas. La ubicación de los tres hombres (mi sujeto es el del medio) en el centro de la toma y notoriamente elevados sobre el resto de las personas fotografiadas (visualmente más pequeñas), genera una idea de dominio y poder. Ninguno de ellos mira a la cámara, sino que se esfuerzan en mostrar sus cuerpos fuertes en la playa. Se ubican en un primer plano, aparentemente deben estar sobre alguna superficie que los eleve (engrandezca) en relación al resto de los ocupantes de la playa. Su pose, en fila (explícitamente acondicionada) es muy distinta a las fotos de los rescates, en las cuales la cámara "subrepticia" registraría a los héroes en el momento de la acción. Esta, como muchas otras del corpus, es una imagen de quietud, de contemplación. La distribución de los personajes, en una armonía perfecta con la línea del horizonte, los sitúa protegiendo el espacio: el mar, pero también al resto de los habitantes de la playa que aparecen en la mitad inferior de la imagen. 
Frente a las numerosas imágenes del momento del rescate que encontré (algunas corresponden a simulacros, otras a verdaderos infortunios: ver fotografía $n^{\circ} 2$ ), mi primera curiosidad fue intentar responder al "para qué" de esas fotos. Busqué, entonces, el reconocimiento social del heroísmo y la hazaña de mi personaje en el diario local La Capital. Fue mi sorpresa la poca resonancia, salvo unas breves referencias a reclamos gremiales o pequeñas notas en la sección de policiales, donde se relatan exiguos conflictos por bañistas indómitos. Deduje que el circuito que perseguían estas imágenes celebratorias no era la crónica de los avatares cotidianos para la prensa.

Según nos contaba su esposa en las entrevistas, estas fotos atesoradas eran regalos que los fotógrafos le hacían a Juan "porque tenía un físico privilegiado". Podría hipotetizar a partir de los intentos por legislar y limitar la cantidad y la actividad de los fotógrafos por parte del Municipio, la condición de "soborno" que estas imágenes poseerían para conseguir la aquiescencia de los guardianes de la playa. ${ }^{10}$ Con sus adulaciones o celebraciones como una figura ejemplar, los fotógrafos contribuían al engrandecimiento de lo que Juan representaba.

\footnotetext{
10 "Reclaman la revisión de una medida los fotógrafos que actúan en Mar del Plata", Diario La Capital, domingo 2 de diciembre de 1945, Archivo Histórico Municipal Roberto T. Barili.
} 
Fotografía $n^{\circ} 2$

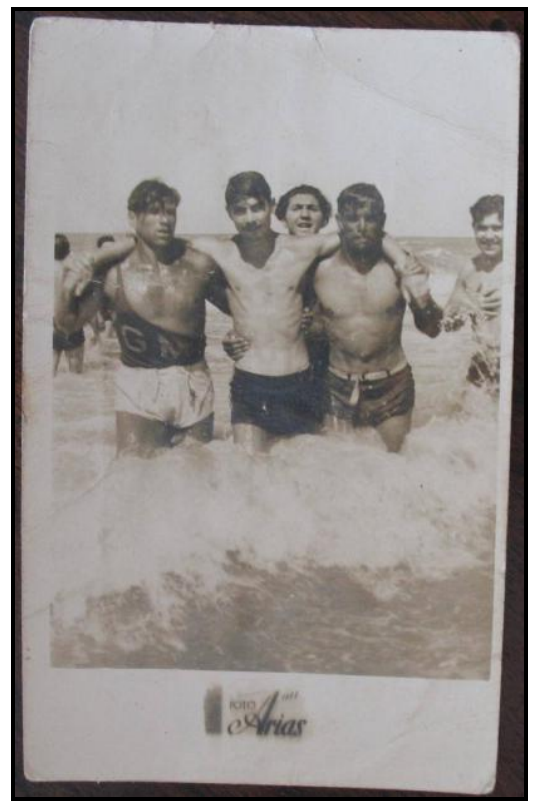

Fuente: Archivo personal de la entrevistada

¿Qué era lo que se perpetuaba o celebraba con los múltiples registros de Juan? La cámara y la fotografía testifican, como una huella, el hecho de que el objeto retratado estuvo ahí, del otro lado. Como decían Barthes y Dubois, en la fotografía necesariamente el referente estuvo delante del obturador. Esa certeza, sumada al efecto documental generado por los usos de las imágenes y por la fascinación técnica propia de la modernidad (o expectativa de veracidad) le confiere al dispositivo fotográfico una fuerza persuasiva diferente a otros registros icónicos.

En la fotografía $n^{\circ} 2$ (1944) lo que la cámara registra y la foto testifica es la hazaña de los guardavidas rescatando a un muchacho. Pero no es la cámara la que actúa sola, si no que el (ojo del) fotógrafo también está allí administrando el espacio y los personajes. Quizás no haya intervenido él sólo en la elección del 
momento, pero el dominio de la técnica le otorga cierto poderío sobre la escena y los objetos (Barrancos y Ceppi, 2005).

En esta imagen, los guardavidas de cuerpo musculoso y bronceado miran a la cámara, mientras que auxilian a un muchacho débil e inexperto. Su apariencia delgada, menos atlética y menos bronceada en comparación con el cuerpo de los guardavidas, añade significados al mismo acontecimiento de ser rescatado.

Pero, además, hay dos personajes más en la foto, en un segundo plano aparecen dos muchachos que también miran a la cámara y sonríen, festejan la proeza. La fotografía no es un acontecimiento individual, sino que varias personas -hombres- se acomodan para ser retratados. Hay una aprobación de la acción por parte de sus congéneres. ¿Qué tipo de acción es certificada en este escenario homosocial? Es la imagen por excelencia del trabajo que realizan los guardavidas, un trabajo que exige fuerza física, valentía, vigor, entrenamiento y conocimiento.

La fotografía $n^{\circ} 3$ (1948), está notablemente manipulada según reglas estilísticas. La línea del horizonte está inclinada y la figura de Juan atraviesa la toma en diagonal. Se repite aquí una de las características comunes de la imagen contemplativa y alerta del espacio de la playa y el mar. Juan no mira directamente a la cámara. Su trabajo que requiere de fuerza, rapidez y acción está representado desde la pasividad absoluta (sus brazos están cruzados y su cabello cuidadosamente peinado). Ni siquiera interpela a la cámara con su mirada. Es una expresión confiada y determinada. El primer plano y la pasividad ¿es un intento de desmarcar la materialidad y "naturaleza" del cuerpo de Juan, es decir, de idealizarlo como un símbolo de los aspectos psicológicos de la masculinidad? Me atrevo a sostener que no es una foto de Juan, es la foto de la fuerza, el autocontrol y la belleza de la masculinidad ejemplar. 
La imagen $n^{\circ} 4$ es distinta del resto de las fotografías hasta aquí comentadas (y de la mayoría del las del corpus ${ }^{11}$ ): Juan está con su esposa posando en la playa. Quizás sea ella, quien aún conserva estas imágenes, un tercer personaje que permita definir el significado de estas imágenes e hipotetizar un sentido de "cuerpo para el amor" de la figura de Juan. La masculinidad ejemplar es una masculinidad heterosexual. El atractivo físico de Juan también está asociado al amor y la pareja: posan uno al lado de la otra, complementarios. Sin embargo, la "necesidad" de una mujer-esposa-madre de tus hijos para concretar la identidad masculina es de orden diferente a la aprobación de los pares que se encuentra en el mismo acto de la toma por profesionales. La complementariedad del hombre y la mujer se no se da en el sentido de "mujer y varón" igual "pareja" o "unidad superior" sino que "varón más mujer" es igual a "varón completo" (Marqués, 1997). La individualidad masculina se resalta en esta toma: constituida a partir de un abanico de significaciones donde la heterosexualidad es una instancia más. El resto de las fotografías están situadas en un ambiente homosocial.

Entre las fotos sueltas que su esposa conserva, se encuentra un álbum de fotos que combina algunas pocas imágenes de su matrimonio (aspecto que refuerza la hipótesis de un sentido romántico de la figura de galán ${ }^{12}$ ) con páginas enteras dedicadas a Juan como guardavidas. La imagen $n^{\circ} 5$ es una de estas.

\footnotetext{
${ }^{11}$ Las únicas mujeres que aparecen fotografiadas en el corpus analizado son su esposa y su hermana.

12 Para la década de 1950 en Argentina, Isabella Cosse (2007) encuentra que en el prototipo de galán de radioteatro romántico que el rol de trabajador del hombre está desconectado de la función proveedora.
} 
Sensibilidades e imágenes generizadas del 'yo' en la década del ' 40



Fuente: Archivo personal de la entrevistada

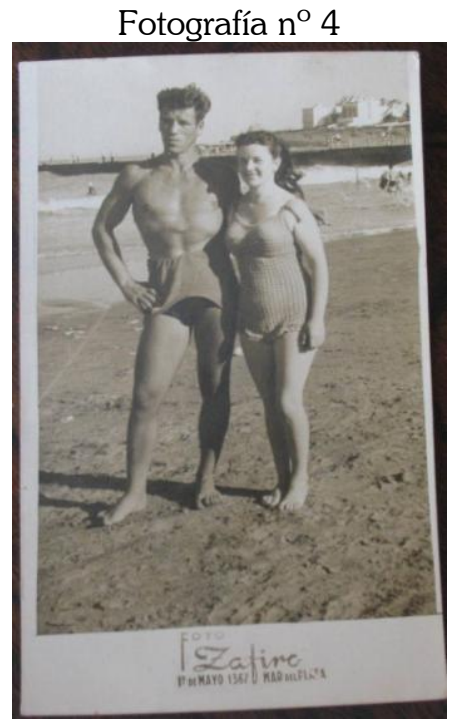

Fuente: Archivo personal de la entrevistada

Fotografía $n^{\circ} 5$

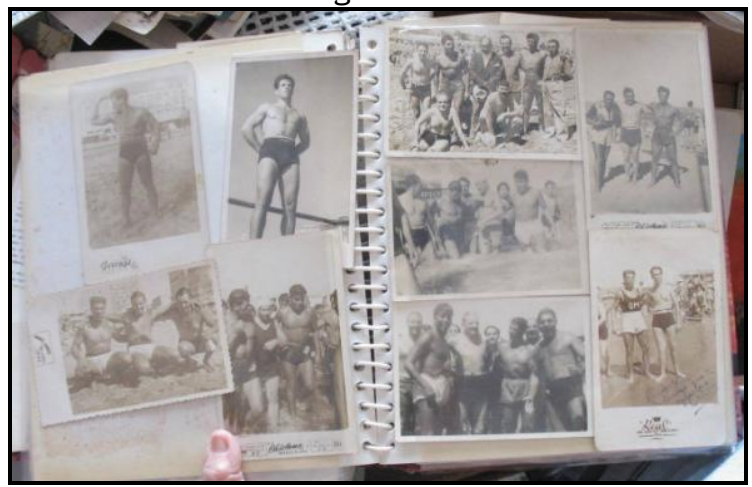

Fuente: Archivo personal de la entrevistada 
En esta paradigmática página del álbum de fotos que Juan tiene dedicado a sus imágenes de guardavidas, los sujetos retratados son todos hombres, la playa se pinta desde estas imágenes como un escenario masculino, lozano y enérgico. En la página de la izquierda, la fotografía de la esquina superior izquierda, lo muestra haciendo una exhibición de su musculatura. En cambio, en la que está inmediatamente a la derecha de ésta, la toma es exageradamente desde abajo hacia arriba, de tal modo, que lo único visible en el fondo es el cielo (algunos techos de edificios en la parte inferior). El engrandecimiento de su figura es intencional, del mismo modo que el fotógrafo siempre encuadra su figura en un primer plano y centrada.

En la página derecha del álbum, Juan no aparece sólo, nuevamente está rodeado de esos otros hombres. ¿Qué significados pose ese montaje? ¿Qué implicancias tienen estas visualidades en las subjetividades masculinas? La admiración entre varones es una precondición de su identificación como hombre, alejado del mundo de las mujeres. No importa tanto el grado de aprendizaje de las pautas varoniles, como que el sujeto se adhiera orgullosamente al colectivo masculino. En el varón la identidad de género es espíritu de cuerpo (Marqués, 1997). La homosocialidad consustancial de la identidad como hombre. En palabras de Michael Kimmel (1997:54-55).

Otros hombres: estamos bajo el cuidado y persistente escrutinio de otros hombres. Ellos nos miran, nos clasifican, nos conceden la aceptación en el reino de la virilidad. Se demuestra hombría para la aprobación de otros hombres: Son ellos quienes evalúan el desempeño.

En la fotografía $n^{\circ} 6$, Juan es fotografiado con otros compañeros y un actor de cine muy popular: Florén Delbene. El Edificio del Casino Provincial está a sus espaldas. Las ropas de los personajes dan cuenta de diferencias sociales entre ellos, sin embargo, éstas se podrían ver desbaratadas en esa escena donde 
posan todos juntos y en una línea. Los pies descalzos de Juan y sus compañeros son un indicio de estas diferencias de clase, pero sus torsos anchos y abdomen terso (si se lo compara con el segundo hombre comenzando de la izquierda) representan la fortaleza de su conquista de una masculinidad asociada al éxito y a los valores del trabajo. La presencia de un actor, otro sujeto masculino ejemplar, también es un indicio del lugar valioso que ocupaban los guardianes del mar en el imaginario masculino. Si bien podría pensarse esta presencia como una concesión por parte del artista, no puedo dejar de resaltar los efectos igualitarios que posee esa toma. Se reproduciría nuevamente la actitud de conquista o logro.

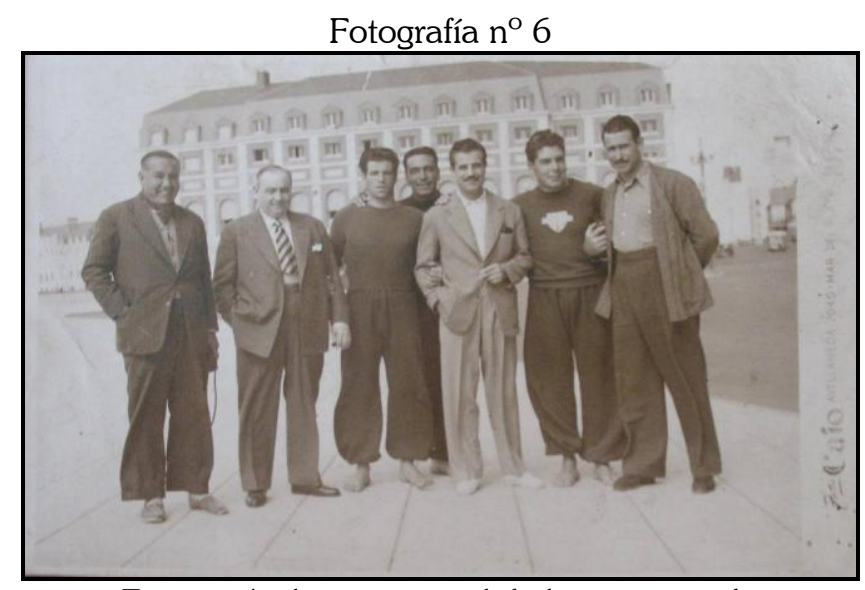

Fuente: Archivo personal de la entrevistada

En la fotografía $n^{\circ} 7$ (1947), la expresividad de la pose y del cuerpo de Juan refuerzan los sentidos que su trabajo posee: enfrentarse al riesgo requiere un cuerpo atlético, fuerte y valiente. 


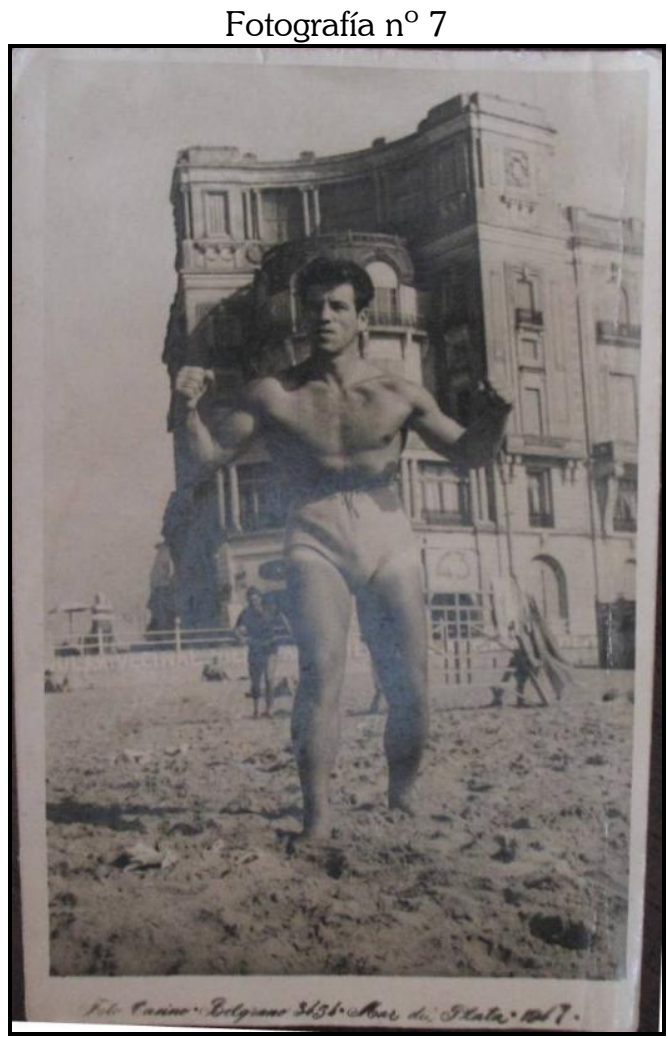

Fuente: Archivo personal de la entrevistada

La magnificencia de Juan está representada aquí no sólo por su pose escultural, sino también por el tamaño de su cuerpo en relación al edificio y a las personas que aparecen en el fondo de la imagen. Los estudios de masculinidades suelen hablar de "embodied masculinities" para hacer referencia a la materialidad de la masculinidad. El cuerpo masculino es el encargado de su identificación como hombre, la vía primordial con la que se presenta ante el mundo:

La forma material del cuerpo masculino está inevitablemente inscrita en la masculinidad. De forma 
similar a que la masculinidad por definición habla a y del (cuerpo) masculino (Whitehead, 2002:183). ${ }^{13}$

Uno de los tópicos de las masculinidades modernas es la idea del hombre auto-creado. Su identificación con el sujeto trascendental de la esfera pública es, sin embargo, coexistente, con una imagen y una materialidad corporal específica. El trabajo sobre el propio cuerpo, el entrenamiento, es un indicio de esta forma de subjetividad que se presenta como autónoma, autogenerada y auto-vigilada. El entrenamiento y el ejercicio físico es parte de esa construcción que se presenta como soberana (Vigarello, 2006). La certidumbre de ganar en seguridad y tenacidad es clave para la construcción de una sensibilidad masculina en este período.

Pero también esta característica de la sensibilidad masculina podría estar posiblemente relacionado con el ideal del asenso social: trabajar sobre uno mismo para tener éxito en la vida. La fotografía $n^{\circ} 7$ tiene como fondo el característico Club Mar del Plata un recinto de la élite que visitaba Mar del Plata a tono con la vieja Rambla y el Hotel Bristol. Juan en esa fotografía no sólo da cuenta de su musculatura, sino que -con su tamaño y postura desafiante- conquista o se re-apropia de los lugares identificatorios de los grupos sociales privilegiados que habitan la ciudad. Con esta imagen se produce una suerte de apropiación de espacios sociales: ocupación legítima en lo que atañe al estereotipo masculino de trabajador (espacio público), pero herético en lo que concierne al grupo social.

La década de 1940 se inicia con un nuevo paisaje urbanístico. La antigua Rambla Bristol (característica del balneario de la belle époque) es demolida y reemplazada por el complejo Casino (se construye en 1938) y Hotel Provincial (su construcción finaliza en 1951). La ciudad comienza a cambiar su fisionomía

13 "The material form of the male body is inevitably inscribed with masculinity. Similarly, that masculinity by definition, speak to and of the male (body)" [Traducción al español de la autora]. 
aristocrática, sin embargo como sostiene Elisa Pastoriza (2002a), no son los trabajadores peronistas los que colman las playas en la década de 1940. La misma imagen de Mar del Plata fue uno de los símbolos del ascenso social (Pastoriza, 2002b).

En aquella imagen, Juan está parado sobre la arena de la playa, pero el recurso de la perspectiva, permite nuevamente una conquista sobre los espacios aristocráticos por parte de un trabajador, quien sólo posee su fuerza y habilidad. ${ }^{14}$ La existencia corporal masculina pone en juego no sólo la ocupación de los espacios, sino su habilidad para definirlo, para ejercer el control sobre él y tener la capacidad de poner en riesgo el propio cuerpo para lograr aquello que se espera de él (Whitehead, 2002).

¿Cuáles son los vínculos que pueden trazarse entre estas estampas de una persona particular y las imágenes que se reunían en la época como arquetipos masculinos? En lo que sigue me propongo rastrear aspectos visuales de las masculinidades en la década del '40, explorando y cotejando algunos estereotipos masculinos en soportes diferentes a la fotografía personal. Anhelo que me permitan esbozar algunas hipótesis sobre las apropiaciones y re-presentaciones de tales imágenes.

\section{4) Cultura física y sensibilidades masculinas en los '40: algunos repertorios}

Las fotografías de Juan podrían ser leídas como las formas en que un sujeto se construye a sí mismo y -si terminara estas especulaciones aquí- podría constatar la existencia de una experiencia masculina particular. Sin embargo, mi hipótesis intenta recuperar los modos en que esas diferenciaciones generizadas son construidas y cómo opera el registro visual en los modos de subjetivación.

Para ello, indagar en repertorios visuales que podrían dialogar con las imágenes de Juan resultaría explicativo en tres

${ }^{14}$ Ver el trabajo de Marcela Gené (2005) sobre la imagen del obrero como héroe positivo y romántico. 
sentidos. En primer lugar, permitiría testear en qué dimensión las imágenes de Juan podrían ser consideradas como parte de una masculinidad ejemplar. Segundo, otras imágenes masculinas similares, pero con una circulación más amplia (en la prensa o en el cine) que la fotografía personal, autorizarían a hipotetizar sobre los modos de apropiación o los diálogos que se establecerían entre las dimensiones macro y micro. Finalmente, la contextualización de los significados visuales de las fotografías de Juan garantizaría mantener en foco las dimensiones sociales de las construcciones del género y las sensibilidades generizadas.

En este apartado exploro y reconstruyo algunos repertorios masculinos en relación a la cultura física en la década del ' 40 . Mi objetivo es rastrear los registros visuales de una masculinidad ejemplar centrada en un cuerpo atlético y vigoroso y -como correlato de tal esculpido muscular- una sensibilidad viril y autocontrolada.

¿Cómo las representaciones de cuerpos masculinos construyen sensibilidades generizadas? ¿Cuál es la relación entre contextura física-entrenamiento y masculinidades en la década del '40? ¿Es posible vincular estas visualidades con los modos de experienciar o actuar la masculinidad en el caso de Juan y sus fotografías?

George Mosse (2000) destaca la cualidad visual del estereotipo/símbolo masculino en las sociedades modernas. Las pretensiones clasificatorias que ensayan la antropología, la fisionomía, la medicina y la psicología son indicios de una centralidad de la relación materialidad-personalidad. En este mismo sentido, la fuerza física y la corporalidad se constituyen como un símbolo de la masculinidad: estándares normativos de apariencia, de conducta y de saber estar.

Los fundamentos de la masculinidad moderna existían, pero fueron sistematizados, convertidos en estereotipo sólo con el inicio de la edad moderna. Ahora la importancia de la estructura real del cuerpo humano se hizo igual - si no 
mayor- que la importancia de sus adornos. El estereotipo de masculinidad se concebía como una totalidad basada en la naturaleza del cuerpo del hombre (Mosse, 2000:9).

Uno de los personajes de la época que se podrían relacionar con las fotografías de Juan es el de las historias de Tarzan del creador Edgar Rice Burroughs. Si bien estas historias cobran visibilidad cinematográfica desde la segunda década del siglo XX, entre 1932 y 1948 se inmortaliza el personaje con la figura de Johnny Weissmuller como Tarzan en las producciones de Metro Goldwyn Mayer: "el tarzan real". Si comparamos la fotografía n ${ }^{\circ} 4$ de Juan con el fotograma tomado de la película "Tarzan and his mate" de 1934, se podrían trazar algunas similitudes simbólicas.

Como la mayoría de los actores que personificaron al "hombre mono", Jonny Weissmuller también fue un atleta (fue nadador olímpico con medallas de oro) que destacaba en las tomas por su contextura corporal, sus proezas físicas y su estilo para moverse en las aguas.

Otra de las similitudes podría encontrarse en el dominio sobre la naturaleza por el hombre sólo. En contraste con la apoteosis de la mecanización y la industrialización de la modernidad, el personaje de Bourrougs recupera al hombre en la naturaleza, que la domina pero a partir de una empatía con ella. Es superior, es el rey de la selva pero se comunica con los animales y los cuida. Hay un reinado sobre la naturaleza (el mar podríamos decir en el caso del heroísmo de los guardavidas) a partir de una superioridad natural. Las fotografías de Juan también están construidas resaltando el dominio sobre el mar y su fuerza física es lo que permite realizarlo.

El grito de Tarzan también es un indicador de su capacidad torácica como símbolo paroxístico de la fuerza física. En varias notas del Diario La Capital de Mar del Plata del año 1945, se recupera esta cualidad en un visitante peculiar como símbolo de su fortaleza sobrehumana. 
Sensibilidades e imágenes generizadas del 'yo' en la década del '40



Johnny Weissmuller y Maureen O'Sullivan

Fotograma de la película "Tarzan and his mate", 1934

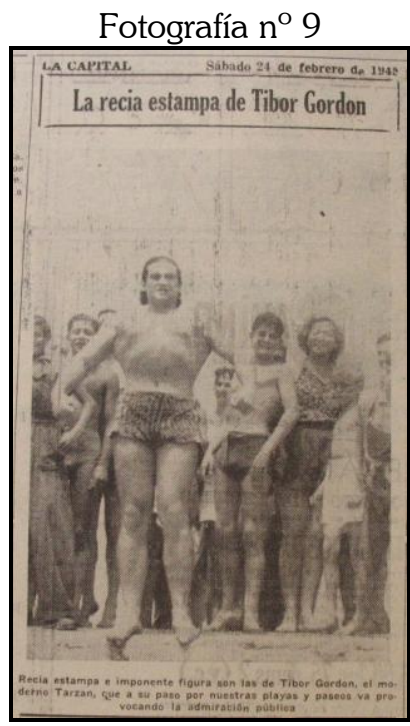

Fuente: Diario La Capital, 24-2-1945

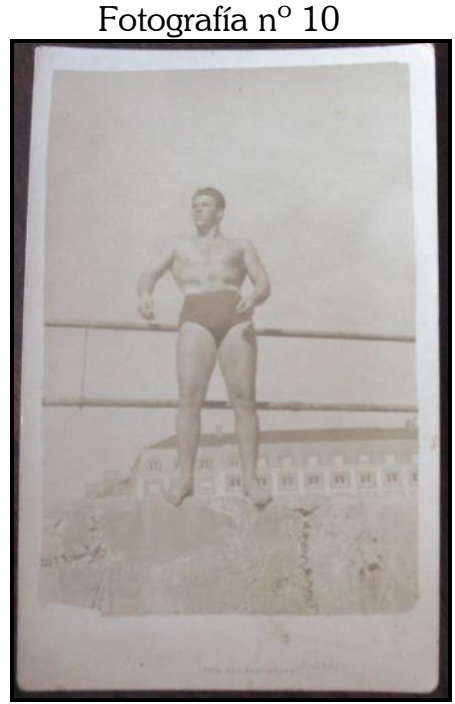

Fuente: Archivo personal de la entrevistada

Archivo Municipal R. T. Barili 
En Febrero de 1945, visita la ciudad Tibor Gordon (ver fotografía n ${ }^{\circ}$ 9), apodado también el "Tarzan real". Su próxima película sería promocionada con una exhibición donde demostraría su fuerza y resistencia colosal. Entre las pruebas que realizaría soportaría

el paso por sobre su cuerpo yacente en tierra, de un camión de seis toneladas, cargado con 25 hombres" y haría "oposición a 20 hombres en diversas demostraciones de fuerza. Sobre su cabeza, cuatro herreros munidos de mazas de 20 kilos descargarán golpes con toda la fuerza que les sea posible. Hará romper sobre su pecho una roca extraída de la costa local, de un peso aproximado o superior a los mil kilos, mediante golpes de maza de varios picapedreros. Doblará hierros de dos pulgadas de diámetro sobre sus hombros. Doblará otros hierros de igual espesor sobre su cabeza. Doblará hierros del máximo diámetro posible con su dentadura. ${ }^{15}$

En la fotografía $n^{\circ}$ 9, Tibor Gordon está rodeado de admiradores, un indicio más de su ejemplaridad como sujeto masculino.

La fotografía $\mathrm{n}^{\circ} 10$ muestra a Juan en una toma que lo engrandece. También, como la de Gordon está fotografiada desde abajo, con el cielo de fondo y una postura que remarca la musculatura de la parte superior de su cuerpo. Se puede vincular con las imágenes de Tarzan donde la cintura fina, el abdomen plano y una espalda amplia con un pecho prominente son valuadas como masculinas, fuertes y más que humanas. La fuerza extrahumana estaba en consonancia con el clima de las guerras. La extraordinaria caja torácica era la metáfora del cuerpo y la raza del superhombre: la parte que representa la fuerza y resistencia.

15 "Tibor Gordon, el Tarzán real, hará una exhibición el domingo", Diario La Capital, 20 de febrero de 1945. 
Otro de los puntos en común entre estas representaciones es que el triunfo sobre la naturaleza o su superioridad corporal es resultado de un trabajo de autoconstrucción. La debilidad que estos personajes habrían padecido en su infancia es contrarrestada por un ejercicio físico individual, constante, voluntarioso que los construye como hombres-héroes.

En el siglo XX la gimnasia se comienza a interpretar como un modo de fortalecer el cuerpo humano (antes se la pensaba como desgaste de las energías del cuerpo). En la primera mitad del siglo $\mathrm{XX}$, se construye la idea de que el ejercicio físico prometería un impacto psicológico:

La difusión de la gimnasia como medio para fortalecer el cuerpo humano fue un paso imprescindible para la perfección del estereotipo masculino, pasando a desempeñar un papel fundamental. El cuerpo en forma, bien esculpido, servía para equilibrar el intelecto, y se pensaba que tal equilibrio era un requisito previo para una moral íntegra, así como para una perfección íntegra (Mosse, 2000:50).

El entrenamiento moviliza (después de la $1^{\text {a }}$ Guerra Mundial) un trabajo sobre la intimidad, el control de lo sensible, la interioridad.

Emerge lentamente un universo que hasta entonces no había estado muy presente en las prácticas corporales: el de los músculos sometidos a esfuerzo, analizados, "conciencizados". El cuerpo se "psicologiza", a imagen del individuo, que se considera más dueño de sí con la modernidad. Aparecen los ejercicios inéditos: "concentre su pensamiento en la respiración, por ejemplo, o 'concentre su atención en el músculo que trabaja, piense en él y trate de sentir cómo realiza su función'. Convertirse en "escultor de la silueta" supone nuevas prospecciones internas, acentuando la densidad del sentimiento íntimo, 
especificando un trabajo inédito sobre el espacio de uno mismo (Vigarello, 2006:179).

El entrenamiento se presenta como una vía en la que el sujeto podría alcanzar el autocontrol e iría dándose forma a sí mismo a modo de autoconstrucción. El sentido del hombre hecho a sí mismo o autotélico se resimboliza en el cuerpo del hombre deportivo.

La relación entre la educación física (el deporte o la ejercitación de los músculos) y el perfeccionamiento físico, moral y psíquico se resalta en algunas investigaciones del período peronista ${ }^{16}$ y puede encontrarse también el la prensa de la época o en los manuales de cultura física. La vigorización de los jóvenes era entendida como una necesidad de la era moderna.

La gimnasia en solitario como un trabajo físico y psicológico de sí mismo también aparece en los populares cursos por correspondencia. Me refiero en particular al manual por correspondencia de Charles Atlas y su método de doce sesiones sin necesidad de aparatos para dejar de ser un "alfeñique" o un avergonzado. Como tantos otros cursos con la misma modalidad de venta, se publicitaba en las revistas de historietas o revistas deportivas.

El Sistema de Tensión Dinámica (también llamado Sistema Atlas) reunía, a modo de los clásicos consejeros de salud, las prescripciones higienistas del siglo XIX y los consejos de salud del siglo $\mathrm{XX}$, donde se cruzaron pericia médica y prácticas populares en materia de salud (Toon y Golden, 2002). Su famoso método comienza a gestarse en la década de 1920 vinculando dos tradiciones: el exhibicionismo muscular de los circos y ferias, y la educación física y el fitness.

La herramienta comercial de Atlas era una historieta de pocos cuadros que mostraban la rápida transformación de José,

\footnotetext{
${ }^{16}$ Ver sobre la promoción peronista del deporte y su relación con la salud, el bienestar y la moralidad los trabajos de Lilia Caimari (2004), Stella Maris Cornelis (2005) y Pablo Scharagrodsky y Ángela Aisenstein (2006).
} 
un "alfeñique", en un hombre musculoso luego de sufrir una ofensa en la playa junto a su pareja. Atlas, cuyo nombre era Angelo Sciciliano, había ganado en 1921 el concurso "World's Most Beautiful Man" creado por Bernarr Macfadden (otro promotor de la cultura física). Hacia fines de los 20 y en un contexto de escaso éxito, creó la publicidad y el sistema de envío por correo y le puso el nombre de "Tensión Dinámica" con su compañero Charles P. Roman. Algunos investigadores sostienen que la audiencia de estos consejos (teniendo en cuenta quiénes le escribían) estaba compuesta por muchachos jóvenes (Toon y Golden, 2002).

Los consejos eran 12 lecciones en entregas por correo mecanografiadas y con formato epistolar que comenzaban con "querido amigo" y terminaban con un alentador saludo y una invitación:

con mis mejores deseos para

su progreso, quedo

Suyo para un Desarrollo Perfecto, Charles Atlas

Z. D. No se olvide de escribir

e informarme cómo marchan

las cosas. ${ }^{17}$

¿Cuál es la transformación que el sistema propone? El llegar a ser hombres perfectos y sanos. ${ }^{18} \mathrm{Y}$ el ejemplar de tal perfección era el mismo Charles Altas que recordaba a sus lectores que él

${ }^{17}$ Lección Primera, archivo personal de la autora.

18 "Ud. también puede ser fuerte. Con pocos minutos diarios, NEW ATLAS SYSTEM le dará a usted un físico recio, varonil, y músculos fuertes y potentes. No hay razón para que usted siga débil y deforme. Cualquier persona, de peso elevado o muy delgada, puede llegar a tener un cuerpo perfecto por nuestro método natural. Si usted necesita ensanchar sus hombros o fortalecer su espalda, desarrollar su sistema muscular, todo esto puede conseguirlo aplicando NEW ATLAS SYSTEM (...) Nuestro método es indicadísimo para los jóvenes que quieran llegar a ser hombres perfectos, sanos y fuertes". Publicidad aparecida en El Gráfico el 19 de enero de 1945. 
también había sido un alfeñique. El método se presenta como una de las vías adquirir la masculinidad: el ejercicio y el cuerpo musculoso permiten alcanzarla.

iYo sé lo que significa el tener una clase de cuerpo que inspira lástima a las gentes! No lo sabe usted bien, desde luego, viéndome a mí ahora, pero yo fui en un tiempo un ALFEÑIQUE debilucho que pesaba solamente $44 \mathrm{~kg}$. Yo mismo me avergonzaba de vestirme en traje de deporte o cuando me desvestía para ponerme el traje de baño. Era un ejemplar de tan lastimoso desarrollo físico que me daba cuenta de ello y me abochornaba. Y esto era causa de que me sintiera solamente VIVO A MEDIAS. ${ }^{19}$

Las fotografías $\mathrm{n}^{\circ} 11$ y $\mathrm{n}^{\circ} 12$ ponen en diálogo la visualidad de Juan y la imagen de Charles Atlas que aparecía en el manual por correspondencia. En el caso de Juan, vuelve a ser recurrente la toma desde abajo y la ausencia de mirada a la cámara. Recorre la playa, la vigila y la cuida. Su musculatura desnuda está expuesta al sol y a la mirada del resto (incluso a la del fotógrafo) mientras que en el fondo en un tamaño más pequeño hay otros hombres vestidos, uno con bata otro con traje blanco, mirando cuando le fotografían. Su cuerpo es la seña de su identidad, su sexo y su clase social.

${ }^{19}$ Publicidad aparecida en El Gráfico 23 de enero de 1942. 
Sensibilidades e imágenes generizadas del 'yo' en la década del '40

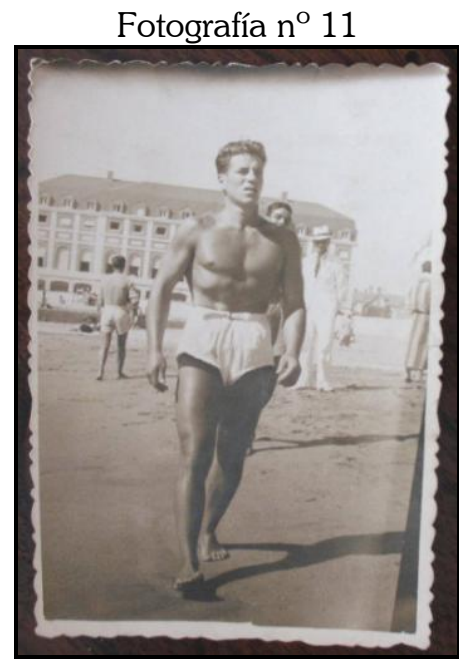

Fuente: Archivo personal de la entrevistada

Fotografía $\mathrm{n}^{\circ} 12$

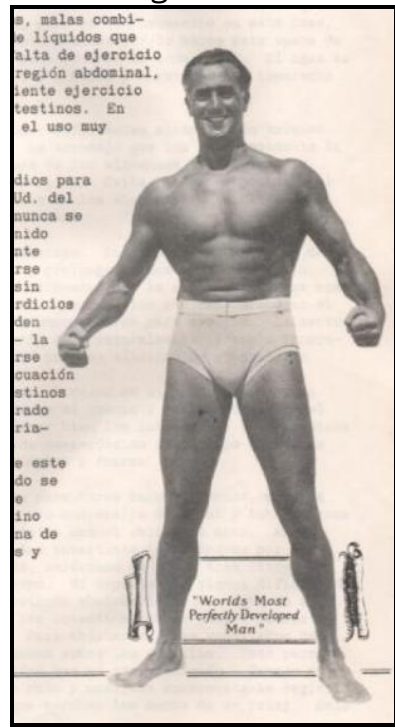

Fuente: Charles Atlas, curso por correspondencia. Archivo personal de la autora. 
Atlas no sólo proponía unos ejercicios, era casi un ritual en solitario: "Entenderá Ud. mejor estas lecciones si las lee en voz alta, en un cuarto donde nadie lo moleste" (Lección 1). Un ritual frente al espejo nos devuelve la analogía entre la condición especular y la fotografía de sí mismo:

Esté seguro de hacer estos movimientos con regularidad TODOS LOS DÍAS sin falta. De ser ello posible, haga estos y todos los otros movimientos delante de un espejo grande, mientras esté desnudo (Lección 1).

Las lecciones tienen un tono muy cercano a los cuidados de la salud, hay capítulos dedicados a la limpieza del cuarto, a la ventilación, a la importancia del agua y al mal del estreñimiento. ${ }^{20}$ Pero también hay otro tipo de simbologías que aquí resultan más pertinentes: la fuerza de voluntad, la perseverancia, el sacrificio y el entusiasmo para lograr un cuerpo bello. Valores todos que pueden asociarse con el ascenso social como significante. La postura correcta y la constancia en la ejecución de los movimientos era central para lograr una "personalidad magnética" y una hombría verdadera. La personalidad estaba re-presentada por la forma física del hombre, su postura, espacialidad y motricidad. El pecho voluminoso y el abdomen plano eran parte de un capítulo especial de este recetario de ejercicios y se observa en las imágenes de Charles Atlas:

Ud. debe hacer cuanto pueda por poseer un pecho VOLUMINOSO por dos razones importantes. Primero, porque le da energía y fuerza extraordinarias al cuerpo entero, y segundo, porque suma a la belleza del contorno desarrollo simétrico que da estampa, figura y confianza en sí. Un tórax redondo y amplio indica fuerza, vitalidad y

${ }^{20}$ En la Lección 3, sobre el estreñimiento, enseña a hacerse uno mismo enemas y la lección 7 está dedicada a la importancia del agua fría y el sol. 
energía sin límite. Asegura un fuerte par de pulmones; un corazón sano y la promesa de una larga vida.

Las recomendaciones de Atlas repercuten en la relación cuerpo y mente; la concentración y la soledad eran la garantía del impacto psicológico de los ejercicios en una personalidad magnética. Hablarse sí mismo (mirase) era una manera de reforzar el grado de masculinidad. El torso fuerte, el abdomen hundido, la motricidad imponente y la compostura erguida eran una manera de no parecer un hombre abandonado sino un hombre potente, un hombre que conquista, que asciende: era una manera de constituirse en hombre.

\section{5) A modo de cierre}

Este trabajo sobre imágenes y género estuvo motivado por una dicotomía que observaba en la producción académica sobre género. Reparaba entonces, que muchos trabajos se esforzaban en probar una experiencia de género (de las mujeres) que había sido negada en las explicaciones socio-históricas. La recuperación del punto de vista y participación de nuevos sujetos se había convertido en una exigencia de la agenda político-académica bajo el ímpetu del feminismo de la segunda ola. Otro grupo de trabajos, quizás en un momento posterior, resaltaban la cualidad social de las construcciones del género. El énfasis puesto sobre los discursos y las relaciones de poder en la constitución de sujetos con género, se convirtió en otro de los núcleos de explicación dentro del feminismo académico.

Advertía, a raíz de estos dos indicios, la ausencia (o la falta de una presencia sistemática) de una vinculación entre experiencias y construcciones que integrara como dimensión explicativa la agencia de los sujetos y la cualidad social de esa agencia.

La incorporación de lo visual en estos procesos de construcción, apropiación y resignificación se me presentaba muy 
atractiva en la investigación de la fotografía personal y familiar. Pero no quería sólo concentrarme en la constatación de una fotografía con particularidades masculinas, sino que me propuse testear el carácter socio-cultural significativo que esas imágenes masculinas tenían. Ampliar la mirada, a modo de hipótesis, a otros estereotipos visuales masculinos fue un intento en este sentido.

A modo de postas en un camino que se está transitando, recapitularé algunas reflexiones a las cuales he llegado en este estudio.

En primer lugar la relación entre apariencia y masculinidad se da por un movimiento de parecer un hombre para luego serlo. La relación entre personalidad y la apariencia es cardinal en el estereotipo masculino moderno. Iris Marion Young (1990) sostiene que a medida que los sujetos se asumen como sujetos generizados, se comportan y se mueven de acuerdo a esa normatividad. ${ }^{21}$ Modificando levemente el orden de este supuesto, propongo una relación más dinámica entre la motricidad, la apariencia y la corporalidad y las formas de generización. Diría en

21 "Hay un estilo específico positivo del comportamiento y movimiento corporal femenino, el cual es aprendido por la niña cuando empieza a comprender que es una niña. La jovencita adquiere muchos hábitos sutiles de comportamiento corporal femenino -caminar como una niña, gesticular como una niña, etc. La niña aprende activamente a suavizar sus movimientos. A ella le dicen que debe ser cuidadosa y no lastimarse, no ensuciarse, no rasgar sus ropas, que las cosas que ella desea son peligrosas. Así, desarrolla una timidez corporal que se incrementa con los años. Al asumir que es una niña, ella misma se considera frágil".

"There is a specific positive style of feminine body comportment and movement, which is learned as the girl comes to understand that she is a girl. The young girl acquires many subtle habits of feminine body comportment -walking like a girl, gesturing like a girl, and so on. The girl learns actively to hamper her movements. She is told that she must be careful not to get hurt, not to get dirty, not to tear her cloths, that the things she desires to do are dangerous for her. Thus she develops a bodily timidity that increases with age. In assuming herself to be a girl, she takes herself to be fragile" (Marion Young, 1990:14) [Traducción al español de la autora]. 
cambio que cuanto más masculino se muestra, más se confirma que "sí, es un hombre".

Relacioné con este "asemejarse a un hombre..." otros estereotipos visuales, otras apariencias masculinas, a modo de hipótesis sobre la ejemplaridad de la masculinidad centrada en la forma del cuerpo y el cuerpo como consecución del sí mismo.

También recuperé el lugar de una materialidad particular (el cuerpo casi desnudo sin ropas, un torso amplio, abdomen hundido, musculoso y con una postura recta), como un paso concluyente para convertirse en un hombre. Un hombre con éxito que domina y controla el espacio: hace que le pertenezca.

El cuerpo como el escenario de un autoconstruirse pone en estrecha relación las categorías de clase y género en sus mutuas definiciones. Ser hombre como un eslabón de ascender socialmente y viceversa. Es el lugar del ejercicio físico como espacio de elaboración de una subjetividad autónoma y autodeterminada lo que entra en juego en este estereotipo masculino.

También planteé el papel importante de los fotógrafos (otros hombres) halagando el tipo de masculinidad que Juan representaba y los significados que esas fotografías podían tener para Juan a modo de certificados de masculinidad. La relación con otros esterotipos altamente estimados en el período como el de Tarzan o los muscle-man, forma parte de esta apropiación de estereotipos. El lugar de la naturaleza como el escenario es un indicio de del sentido que la "soledad" como autonomía o autoconstrucción cobra en la subjetividad masculina. ${ }^{22}$

Finalmente, como muchos otros trabajos han recuperado, es importante también aquí la cualidad homosocial del proceso de construcción de la subjetividad masculina, donde es el propio grupo de pares y los criterios masculinos los legitiman cuán masculino uno es. Los fotógrafos son parte de este grupo de

\footnotetext{
22 Retomo acá el sugerente planteo de Soledad Murillo (2006) para quién el cultivo del sí mismo, propio de la esfera privada es absolutamente una característica masculina.
} 
iguales. A diferencia de identificaciones como mujeres que suelen ser: "madres de hombres", "hijas de hombres", "esposas de hombres", la masculinidad es homosocialmente legitimada. Para los hombres, la heterosexualidad es un elemento más en el abanico de condiciones de su hombría.

Contemplarse a uno mismo en una fotografía es una mirada de ida y vuelta, donde se entrecruzan los ya vistos.

\section{Referencias bibliográficas}

BARRÁn, José Pedro. Historia de la sensibilidad en el Uruguay. Montevideo, Ediciones de la Banda Oriental, 1990.

BARRANCOS, Dora y CEPPI, Ricardo. Sexo-s en el lupanar: un documento fotográfico (circa 1940). Cadernos Pagu (25), Campinas-SP, Núcleo de Estudos de Gênero-Pagu/Unicamp, 2005, pp.357-390.

BARTHES, Roland. La cámara lúcida. Nota sobre fotografía. Buenos Aires, Paidós, 2003.

BONNER, Frances y otros. (eds.) Imagining Women. Cultural Representations and Gender. Cambridge, Polity Press/The Open University, 1992.

BURKE, Peter. Visto y no visto. El uso de la imagen como documento histórico. Barcelona, Crítica, 2001.

CAIMARI, Lilia. Apenas un delincuente: crimen, castigo y cultura en la Argentina, 1880-1955. Buenos Aires, Siglo XXI, 2004.

CORNELIS, Stella Maris. Control y generización de los cuerpos durante el peronismo: La educación física como transmisora de valores en el ámbito escolar (1946-1955). La Aljaba (9), Luján-La PampaComahue, 2005, pp.105-121.

COSSE, Isabella. Relaciones de pareja a mediados de siglo en las representaciones de la radio porteña: entre sueños románticos y visos de realidad. Estudios Sociológicos (73), El Colegio de México, 2007, pp.131-153.

De LAURETIS, Teresa. Alicia ya no. femisnismo, semiótica y cine. Madrid, Cátedra, 1992. 
Sensibilidades e imágenes generizadas del 'yo' en la década del '40

DuBoIS, Philippe. El acto fotográfico. De la representación a la recepción. Barcelona, Paidos, 1982.

ELíAS, Norbert. El proceso de la civilización. Investigaciones psicogenéticas y sociogenéticas. Buenos Aires, Fondo de Cultura Económica, 1993.

FREUND, Gisèlle. La fotografía como documento social. Barcelona, Gustavo Gili, 1993.

GENÉ, Marcela. Un mundo feliz. Imágenes de los trabajadores en el primero peronismo, 1946-1955. Buenos Aires, FCE/San Andrés, 2005.

HAYES, Patricia. Introduction: Visual Genders. Gender \& History, vol. 17, n 3, November 2005, pp.519-537.

KIMMEL, Michael. Homofobia, temor, vergüenza y silencio en la identidad masculina. In: VALDÉS, Teresa y OLAVARRÍA, Juan. Masculinidades poder y crisis. Isis Internacional, no 24, Chile, 1997.

KossoY, Boris. Fotografía e Historia. Buenos Aires, La Marca Editora, 2001.

KuHN, Annette. Power of the Image: Essays on Representation and Sexuality. New York, Routledge \& Kegan Paul Books, 1994.

LAGUARDA, Paula. Cine y estudios de género: imagen, representación $e$ ideología. Notas para un abordaje crítico. La Aljaba (10), Luján-La Pampa-Comahue, ene./dic., 2006, pp.141-156.

MARION YOUNG, Iris. Throwing like a girl. A Phenomenology of feminine body comportment, motility and spatiality. In: MARION YOUNG, I. Throwing like a girl and other essays in feminist philosophy and social theory. Indiana University Press, Indianapolis, 1990.

MARQUÉS, J-V. Varón y patriarcado. In: VALDÉS, Teresa y OlAVARRíA, Juan. Masculinidades poder y crisis. Isis Internacional, $n^{\circ} 24$, Chile, 1997.

MichAUD, Yves. Visualizaciones. El cuerpo y las artes visuales. In: CORBIN, Alain; COURTINE, Jean Jaques y VigARELlO, Georges. (dirs.) Historia del Cuerpo III. Las mutaciones de la mirada. El siglo XX. Madrid, Taurus, 2006. 
MossE, George. La imagen del hombre. La creación moderna de la masculinidad. Madrid, Talasco Ed., 2000.

MULVEY, Laura. Visual and other pleasures. Indiana, Indiana University Press, 1989.

MuRILlo, Soledad. El mito de la vida privada. De la entrega al tiempo propio. Madrid, Siglo XXI, 2006.

ORY, Pascal. El cuerpo ordinario. In: CORBIN, Alain; COURTINE, Jean Jaques y VigARELlO, Georges. (dirs.) Historia del Cuerpo III. Las mutaciones de la mirada. El siglo XX. Madrid, Taurus, 2006.

PASTORIZA, Elisa. Los primeros pasos hacia un balneario de masas. Mar del Plata en los años treinta. In: BARTOLUCCI, Mónica. (ed.) Mar del Plata. Imágenes urbanas, vida cotidiana y sociedad. Mar del Plata, Facultad de Humanidades/UNMdP, 2002a.

. Turismo social y acceso al ocio: el arribo a la ciudad balnearia durante las décadas peronistas (Mar del Plata, 1943-1955). In: Pastoriza, E. (ed.) Las puertas al mar. Consumo, ocio y política en Mar del Plata, Montevideo y Viña del Mar. Buenos Aires, Biblos, 2002.

POLLOCK, Griselda. Missing Women: Rethinking early thoughts on Images of Women. In: SQUIERS, Carol. (ed.) Over Expossed. Essays on Contemporary Photography. New York, The New Press, 2000.

PULTZ, John. La fotografía y el cuerpo. Madrid, Akal, 1995.

ScotT, Joan. Experiencia. Hiparquía, vol. X, nº 1, Julio 1999.

SHIACH, Morag. (ed.) Feminism and Cultural Studies. Nueva York, Oxford University Press, 1999.

SONTAG, Susan. Sobre la fotografía. Barcelona, Edhasa, 1996.

TOON, Elizabeth y GOLDEN, Janet. Live clean, think clean, and don't go to burlesque shows: Charles Atlas as health advisor. Journal of the History of Medicine (57), January 2002, pp.39-60.

TORRICELlA, Andrea. Apropiaciones y distanciamientos en las representaciones familiares. Argentina, 1930-1960. Trabajo presentado en el Congreso Internacional "Familias y Organización 
Sensibilidades e imágenes generizadas del 'yo' en la década del ' 40

Social en Europa y América", Murcia-Albacete, del 12 al 14 de diciembre de 2007.

e Pérez, Inés. Memoria de género y biografía familiar. Revista Argentina de Sociología (4), Consejo de Profesionales de Sociología, Buenos Aires, mayo-junio de 2005, pp.99-116.

Vigarello, Georges. Entrenarse. In: CorBIN, Alain; CourTine, Jean Jaques y Vigarello, G. (dirs.) (dirs.) Historia del Cuerpo III. Las mutaciones de la mirada. El siglo XX. Madrid, Taurus, 2006.

SCHARAGRODSKY, Pablo y AISENSTEIN, Ángela. Tras las huellas de la Educación Física Escolar Argentina. Cuerpo, Género y Pedagogía 1880-1950. Buenos Aires, Prometeo Libros, 2006. 